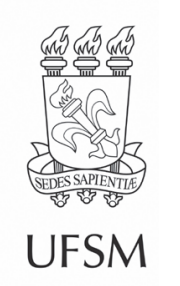

\title{
Artigos
}

\section{Fenologia de Lafoensia pacari St. Hill. em duas fitofisionomias do Cerrado Mato-Grossense}

\author{
Fenology of Lafoensia pacari St. Hill. in two vegetation types of Cerrado \\ Mato-Grossense
}

\author{
Reinaldo de Souza Bílio' ${ }^{\oplus}$, Maria de Fatima Barbosa Coelho ${ }^{\bullet}$, \\ Elisângela Clarete Camili' ${ }^{\oplus}$, Flávia Richelli Pirani" ${ }^{\oplus}$, \\ Simone dos Santos da Silva"I" $\odot$ \\ 'Universidade Federal de Mato Grosso, Cuiabá, MT, Brasil \\ "Pesquisadora Autônoma, Barra do Garças, MT, Brasil \\ "'Pesquisadora Autônoma, Cuiabá, MT, Brasil
}

\section{RESUMO}

O objetivo deste trabalho foi avaliar a fenologia de Lafoensia pacari St. Hill. em duas áreas de Cerrado Mato-Grossense que se distinguem pela fitofisionomia: Cerradão e Cerrado sentido restrito, entre fevereiro de 2015 a janeiro de 2017, utilizando o índice Fournier. Correlacionaram-se as fenofases queda de folhas, brotação, floração e frutificação, com as variáveis ambientais: temperaturas máxima e mínima, umidade relativa e precipitação. A queda foliar ocorreu nos meses de julho e agosto de 2015, com 80 e 84\%, e em 2016 entre agosto e setembro com 92 e $88 \%$ nas áreas 1 e 2, respectivamente. A queda das folhas se intensificou no auge do período de seca nas duas áreas. A brotação se iniciou no período chuvoso nas duas áreas. Botões florais foram observados no final do período chuvoso e por todo o período seco nas áreas 1e 2, entre os meses de maio a julho de 2015. Em 2016, os botões florais foram observados de abril a agosto na área 1 e em março na área 2. Na área 1, o pico de intensidade dos botões florais ocorreu em junho de 2015 e em maio de 2016, com 14 e 25\%, respectivamente. O índice de intensidade de botões foi inferior a 2\% na área 2. O pico de intensidade da antese na área 1 ocorreu em maio de 2015 e em junho de 2016, com 9 e 17\%, respectivamente. O índice de intensidade de floração atingiu valores inferiores a $2 \%$ na área 2 . 0 índice de intensidade de frutos imaturos e maduros apresentou valores inferiores a 8 e 5\%, respectivamente, na área 1. Na área 2, não foi observado o processo de frutificação. Lafoensia pacari apresentou intensa senescência das folhas no auge do período seco. Os indivíduos da área de Cerradão apresentaram maior desempenho, principalmente das fenofases reprodutivas.

Palavras-chave: Espécie nativa; Fenofases; Fournier; Mangava-brava 


\section{ABSTRACT}

The objective of this work was to evaluate the phenology of Lafoensia pacari St. Hill. in two areas of Cerrado Matogrossense that are distinguished by phytophysiognomy: Cerradão and Cerrado restricted sense, between February 2015 to January 2017, using the Fournier index. Leaf fall, budding, flowering and fruiting phenophases were correlated with the environmental variables: maximum and minimum temperatures, relative humidity and precipitation. The fall of leaves occurred in July and August 2015, with 80 and 84\% and, in 2016 in August and September with 92 and 88\% in areas 1 and 2, respectively. Leaf fall intensified at the height of the dry season in both areas. Sprouting started in the rainy season in both areas. Flower buds were observed at the end of the rainy season and throughout the dry season, in areas 1 and 2, from May to July 2015. In 2016, flower buds were observed and from April to August in area 1 and in March in area 2. In area 1, the peak intensity of flower buds occurred in June 2015 and in May 2016, with 14 and 25\%, respectively. The button intensity index was less than 2\% in area 2 . The peak anthesis intensity in area 1 occurred in May 2015 and in June 2016, with 9 and 17\%, respectively. The flowering intensity index reached values below $2 \%$ in area 2 . The intensity index of immature and ripe fruits showed values below 8 and $5 \%$, respectively, in area 1. In area 2, the fruiting process was not observed. Lafoensia pacari showed intense leaf senescence at the height of the dry period. Individuals from the Cerradão area showed higher performance, mainly in reproductive phenophases.

Keywords: Native species; Phenophases; Fournier; Mangava-brava

\section{INTRODUÇÃO}

Através dos estudos fenológicos é possível prever a época de reprodução, deciduidade e ciclo de crescimento vegetativo, essas informações podem ser utilizadas para o manejo adequado das espécies (MORELLATO et al., 2016).

A fenologia é considerada uma ferramenta útil no planejamento do manejo das florestas tropicais, gerando informações sobre a época mais propícia para colheita de sementes, e também indicando quais espécies podem ser introduzidas em plantios como fonte de alimento para a fauna, em épocas distintas do ano (PEREIRA et al., 2008).

Dentre os fatores que influenciam os eventos fenológicos, se destacam a luz, a temperatura, os nutrientes e a precipitação. Esses fatores abióticos essenciais podem limitar direta e indiretamente a fase reprodutiva e vegetativa da planta, além dos fatores bióticos, como polinização, modo de dispersão das sementes, patógenos e herbivoria, que também são importantes na floração de espécies vegetais (RANTHCKE; LACEY, 1985). 
As espécies lenhosas do Cerrado podem apresentar períodos distintos de floração, frutificação e dispersão das sementes, provando que apresentam estratégias distintas de ajustamento aos condicionantes bióticos e abióticos (MUNHOZ; FELFILI 2007; OLIVEIRA 2008).

A Lafoensia pacari, popularmente conhecida como mangava-brava ou dedaleiro, é geralmente utilizada para tratar úlceras, câncer, gastrite, favorece o emagrecimento, uma melhor cicatrização e é anti-inflamatória. As partes da planta mais utilizadas são: casca, raízes e folhas (CABRAL; PASA, 2009).

Em razão do grande potencial medicinal da espécie, suas populações naturais são constantemente alvo do extrativismo predatório. Diante disso, torna-se urgente a proposição de estudos que contribuam para o entendimento do processo de reprodução e regeneração das plantas nativas, bem como informações quanto ao seu comportamento fenológico (PIRES et al., 2016), que futuramente poderão embasar ações e projetos de recuperação das áreas degradadas.

A baixa disponibilidade de estudos sobre fenologia para uma grande parcela das espécies reforça a necessidade da realização de pesquisas sobre esta temática em regiões bioclimáticas específicas (FREIRE et al., 2013). Desse modo, pesquisas sobre a biologia floral de espécies arbóreas do Cerrado, como fonte de informação sobre a singularidade de cada espécie e sobre a dinâmica que rege os organismos que compõem o bioma, permitem compreender como as plantas do cerrado estão se adaptando às mudanças locais e como tais mudanças afetam seu sucesso reprodutivo (SANTOS; AÑEZ, 2018), bem como estudos que visam à caracterização das fenofases vegetais são relevantes para o entendimento da dinâmica das populações, funcionando como indicadores das respostas das plantas às condições climáticas e edáficas locais (FOURNIER, 1974).

A partir disso, o objetivo deste estudo foi avaliar a fenologia de Lafoensia pacari St. Hill. em duas áreas de Cerrado que se diferenciam pela fitofisionomia, relacionando os dados fenológicos com fatores ambientais, tais como: temperatura, umidade relativa e precipitação. 


\section{MATERIAL E MÉTODO}

\section{1 Área de estudo}

Este trabalho foi desenvolvido em uma propriedade particular a $15 \mathrm{~km}$ de Cuiabá ( $15^{\circ} 43^{\prime}$ Sul e $56^{\circ} 04^{\prime}$ Oeste). A área é de Cerrado com camada relativamente contínua de gramíneas e de pequenas árvores e arbustos.

O clima da área, segundo a classificação de Köppen, é do tipo Aw, com temperatura média anual de $26^{\circ} \mathrm{C}$, e precipitação média anual de $1420 \mathrm{~mm}$. O local é plano com uma elevação média de 157 m, localizado dentro de uma área de 54.522 $\mathrm{km}^{2}$ (DALMOLIN et al., 2015).

As duas áreas de estudo da propriedade se diferenciam principalmente pela cobertura vegetal. A primeira área foi caracterizada por vegetação típica de Cerradão (Área 1), com presença de espécies que ocorrem no Cerrado sentido restrito e por espécies de mata. Os indivíduos desta área apresentam copas contínuas e altura média do estrato arbóreo entre 8 a 15 metros, o que resulta em condições de luminosidade que beneficiam o estrato herbáceo e arbustivo. A segunda área foi caracterizada por vegetação de Cerrado sentido restrito (Área 2) com árvores inclinadas, de menor porte, tortuosas e com ramificações retorcidas e irregulares. Os indivíduos estão mais distanciados entre si, e o sub-bosque é caracterizado como pouco denso.

\subsection{Seleção dos indivíduos amostrados e dados fenológicos}

Foram demarcados 50 indivíduos de Lafoensia pacari, sendo 25 indivíduos localizados no Cerradão e 25 no Cerrado sentido restrito. Os indivíduos selecionados estavam em idade reprodutiva e apresentavam boa visibilidade da copa.

As observações fenológicas foram realizadas a cada quinze dias, de fevereiro de 2015 a janeiro de 2017, em que se registrou a ocorrência das seguintes fenofases:

i) brotação: aparecimento de brotos foliares até a expansão das folhas novas;

ii) queda das folhas; iii) floração: produção de botões florais e antese; iv) frutificação: frutos imaturos e frutos maduros. 
As fenofases observadas foram relacionadas com os seguintes dados meteorológicos da área: precipitação acumulada mensal, média mensal da umidade relativa do ar, e médias das temperaturas máxima e mínima mensais. Os dados de umidade relativa e das temperaturas foram obtidos através de uma estação situada na propriedade, e os dados de precipitação através do INMET (Instituto Nacional de Meteorologia).

\subsection{Análise dos dados}

Os dados das duas áreas foram analisados separadamente:

- Porcentagem de intensidade de Fournier (FOURNIER, 1974): Observação através de uma escala intervalar semiquantitativa com cinco categorias com variação de 0 a 4 e intervalo de $25 \%$ entre cada categoria. Categoria (0) ausência do evento fenológico; (1) presença do evento de 1 a 25\%; (2) presença do evento de 26 a 50\%; (3) presença do evento de 51 a 75\% e (4) presença do evento de 76 a 100\%.

- Índice de atividade (porcentagem de indivíduos): É um método simples, que constatou somente a presença ou ausência da fenofase no indivíduo. Esse método indica a porcentagem de indivíduos da população que está manifestando determinado evento fenológico (BENCKE; MORELLATO, 2002).

Foi utilizado o coeficiente de correlação de Spearman $\left(r_{s}\right)$ para verificar a relação entre as fenofases e as variáveis climáticas, através do número de indivíduos observados mensalmente em cada fenofase (ZAR, 1996).

\section{RESULTADOS E DISCUSSÃO}

No período do estudo, de fevereiro de 2015 a janeiro de 2017, foi observada a sazonalidade climática (Figura 1), com dois períodos chuvosos, dois períodos secos, dois períodos de transição chuvoso-seco e dois períodos de transição seco-chuvoso.

O período chuvoso, no ano de 2015, teve início em novembro e foi até abril de 2016, que concentrou os maiores índices de precipitação (alcançando até 250 mm). 
Nos meses de maio, junho e julho de 2016, a precipitação foi baixa (alcançando no máximo $10 \mathrm{~mm}$ ), evidenciando o período seco. Nos meses de agosto e setembro de 2016 houve um aumento gradativo das chuvas, e em outubro do mesmo ano iniciouse um novo período úmido. Não houve precipitação nos meses de agosto de 2015 e julho de 2016, e o mês que mais choveu durante todo o período de observação foi fevereiro de 2015, com precipitação acumulada de $328,6 \mathrm{~mm}$. Os períodos de seca nos anos de 2015 e 2016 se estenderam por apenas três meses.

Figura 1 - Médias mensais das temperaturas máxima (Tmáx) e mínima (Tmín), média mensal da umidade relativa (UR) do ar e precipitação mensal acumulada (PPT) entre os meses de fevereiro de 2015 e janeiro de 2017

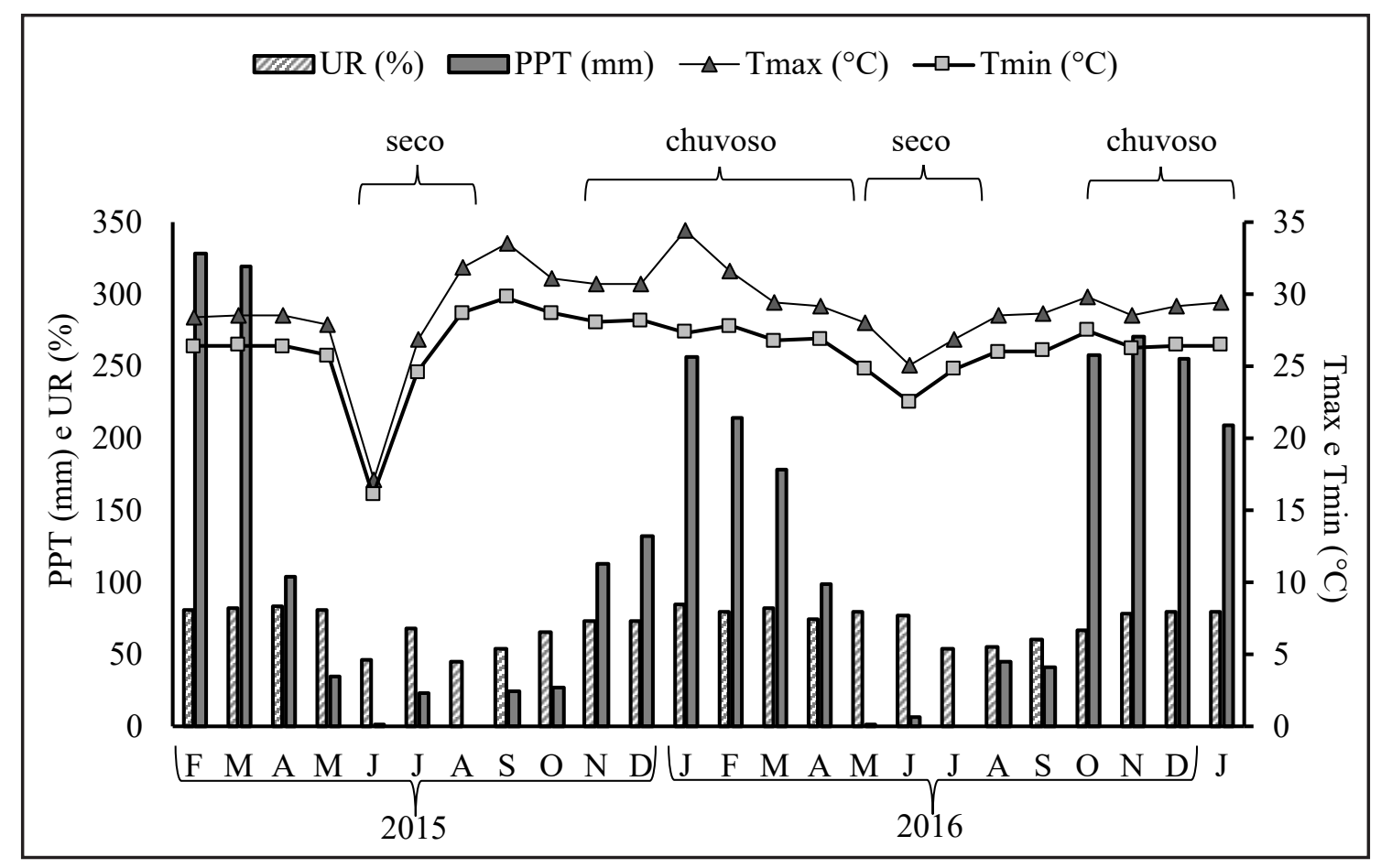

Fonte: Autores (2020)

\subsection{Fenofases vegetativas}

O pico de queda foliar de Lafoensia pacari ocorreu entre julho e agosto de 2015, nas áreas 2 e 1, respectivamente, com 80 e 84\% dos indivíduos apresentando o evento. 
O pico de queda de folhas, em 2016, ocorreu em agosto e setembro nas duas áreas. Na área 2, 92\%, e na área 1, 88\% dos indivíduos perderam as folhas.

O índice de intensidade de queda foliar foi de 75 e $72 \%$ nos meses de julho e agosto de 2015 nas áreas 2 e 1, respectivamente. A intensidade de queda de folhas atingiu 80 e 82\% nas áreas 1 e 2, respectivamente, em agosto do ano de 2016 (Figura 2).

Figura 2 - Índice de atividade (a) e (b), e de intensidade (c) e (d) em relação à queda e brotação de folhas de 50 indivíduos amostrados de Lafoensia pacari St Hill., em duas áreas de Cerrado Mato-Grossense

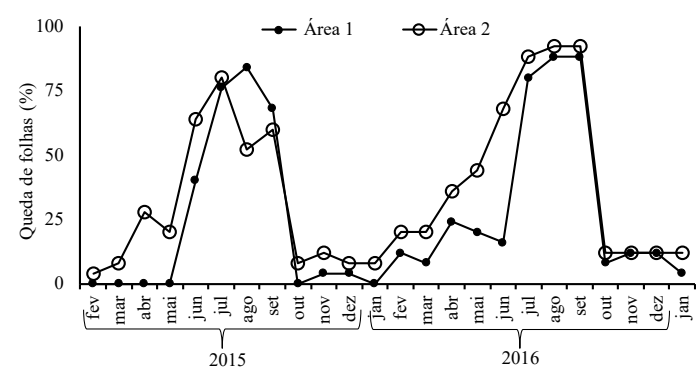

A
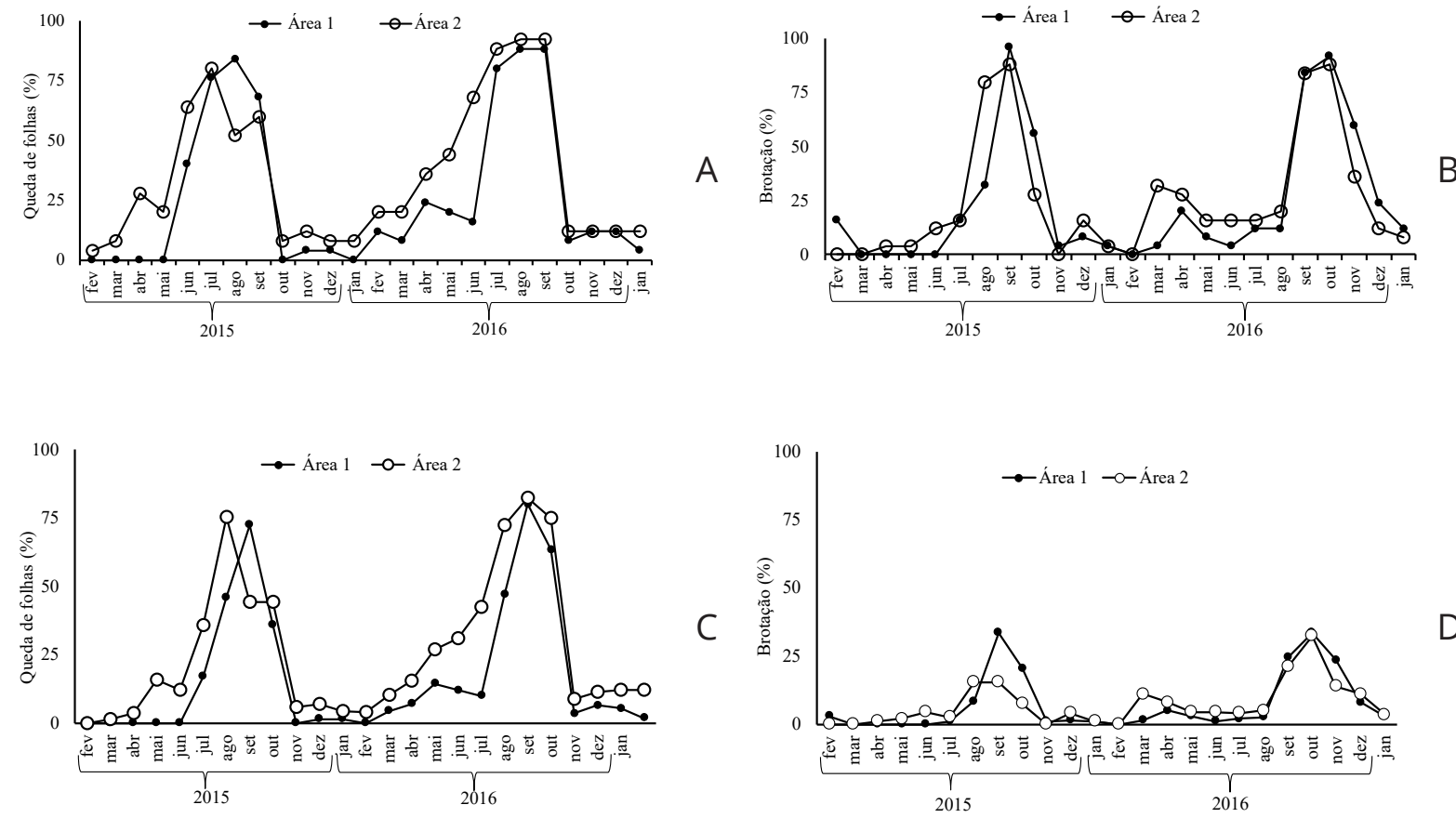

Fonte: Autores (2020)

Observou-se que a queda das folhas se intensificou no auge do período seco, o que ficou evidente através das correlações negativas das duas áreas com as variáveis. $\mathrm{Na}$ área 1, a queda foliar correlacionou-se negativamente com as variáveis UR $\left(r_{\mathrm{s}}=\right.$ $-0,73)$ e precipitação $\left(r_{s}=-0,59\right)$. Na área 2 , o evento correlacionou-se negativamente com todas as variáveis climáticas analisadas. Tais resultados atestam a queda de folhas, predominantemente no período seco, nas duas áreas de estudo (Tabela 1). 
De fato, esse comportamento é esperado em regiões de clima sazonal com período seco evidente. Ao acompanhar o comportamento fenológico de algumas espécies lenhosas em um Cerrado sentido restrito em Brasília-DF, Furquim et al. (2018) abordaram que além da capacidade de controlar a abertura estomática, as espécies reduzem a folhagem no período mais seco como uma estratégia adicional na redução da perda de água, ou seja, a perda é uma resposta da vegetação que, com a queda de folhas, minimiza a perda de água por transpiração (SILVA et al., 2007).

Tabela 1 - Coeficientes de correlação de Spearman $\left(r_{s}\right)$ entre precipitação total mensal, temperatura máxima, temperatura mínima e umidade relativa e a porcentagem de indivíduos de Lafoensia pacari St. Hill., nas fenofases queda foliar (Q) e brotação (Br)

\begin{tabular}{|c|c|c|c|c|c|c|}
\hline \multirow[b]{2}{*}{ Variável ambiental } & \multicolumn{3}{|c|}{ Área 1} & \multicolumn{3}{|c|}{ Área 2} \\
\hline & Fenofase & $r_{s}$ & $\mathbf{p}$ & Fenofase & $r_{s}$ & $\mathbf{p}$ \\
\hline \multirow{2}{*}{ UR (\%) } & $\mathrm{Q}$ & $-0,73$ & 0,0001 * & $\mathrm{Q}$ & $-0,55$ & $0,004 *$ \\
\hline & $\mathrm{Br}$ & $-0,50$ & 0,01 * & $\mathrm{Br}$ & $-0,58$ & $0,002 *$ \\
\hline \multirow{2}{*}{ Temp. Máx. $\left({ }^{\circ} \mathrm{C}\right)$} & $\mathrm{Q}$ & $-0,18$ & 0,38 & $\mathrm{Q}$ & $-0,41$ & $0,04 *$ \\
\hline & $\mathrm{Br}$ & 0,28 & 0,17 & $\mathrm{Br}$ & 0,18 & 0,39 \\
\hline \multirow{2}{*}{ Temp. Mín. $\left({ }^{\circ} \mathrm{C}\right)$} & $\mathrm{Q}$ & $-0,27$ & 0,19 & $\mathrm{Q}$ & $-0,50$ & $0,012 *$ \\
\hline & $\mathrm{Br}$ & 0,29 & 0,16 & $\mathrm{Br}$ & 0,16 & 0,44 \\
\hline \multirow{2}{*}{ Precipitação (mm) } & $\mathrm{Q}$ & $-0,59$ & $0,002 *$ & $\mathrm{Q}$ & $-0,74$ & $0,0001 *$ \\
\hline & $\mathrm{Br}$ & $-0,02$ & 0,89 & $\mathrm{Br}$ & $-0,32$ & 0,12 \\
\hline
\end{tabular}

Fonte: Autores (2020)

Em que: (*) Correlação significativa a $5 \%$ de probabilidade $(p<0,05)$.

Foi observado também um padrão sazonal nas fenofases vegetativas de Lafoensia replicata Pohl. em uma área de transição entre os biomas Cerrado e Caatinga, localizada no município de Bom Jesus, sul do Estado do Piauí (PIAUILINO et al., 2012), demonstrando uma tendência deste comportamento nas espécies do gênero que ocorrem no Cerrado brasileiro.

Nos dois anos avaliados, Lafoensia pacari apresentou queda das folhas nos 
meses de julho a setembro, períodos que coincidiram com as épocas secas dos anos, ou com a retomada dos períodos chuvosos. Faria et al. (2015), ao estudarem a fenologia de Brosimum gaudichaudii em um Cerrado sentido restrito localizado na comunidade de Mata Cavalos-MT, observaram que além da precipitação, menores temperaturas, principalmente no mês de julho, favoreceram a senescência das folhas da espécie.

Santos, Coelho e Pirani (2009) verificaram em uma área de Cerrado sentido restrito localizada em Barra do Garças-MT, um padrão de queda de folhas similar ao deste estudo. A abscisão das folhas de Lafoensia pacari iniciou-se no mês de julho de cada ano de avaliação e apresentou maior intensidade nos meses de setembro de 2004 e 2005, com 98 e 100\%, respectivamente. Os autores indicaram que a queda foliar mostrou correlação negativa com a temperatura mínima e com a precipitação, e que a correlação entre queda foliar e diminuição da pluviosidade sugere este fator como desencadeador do processo.

Esse comportamento de queda foliar nos meses mais secos do ano vai ao encontro da maioria das espécies de ocorrência no Cerrado brasileiro. Qualea parviflora iniciou a queda das folhas nos meses de junho e julho de 2011 e 2012, respectivamente. Os indivíduos da espécie permaneceram sem folhas durante o período mais seco e frio do ano (FERREIRA et al., 2017). O mesmo comportamento de perda das folhas no período seco também foi observado nos estudos de Souza et al. (2014) e Braga et al. (2019), em uma área de caatinga e de transição Cerrado-Caatinga, respectivamente.

Logo após a ocorrência da queda foliar, observou-se o início dos primeiros brotos foliares. A brotação das folhas foi observada de julho a outubro de 2015 na área 1, e de junho a outubro de 2015 na área 2. Nas áreas 1 e 2, 96 e 88\% dos indivíduos apresentaram o máximo de brotação no mês de setembro, respectivamente.

No ano de 2016, a brotação foliar ocorreu de setembro a dezembro nas duas áreas. O pico de brotação nesse ano ocorreu em outubro, em que 92\% dos indivíduos 
na área 1 e, 88\% dos indivíduos na área 2, registraram o evento (Figura 2).

Santos, Coelho e Pirani (2009) observaram a fenofase de brotação de Lafoensia pacari de outubro a dezembro em 2004 e de setembro a novembro em 2005, com maior intensidade no início do período chuvoso, ou seja, a mesma variação da fenofase entre os anos de avaliação observada neste estudo.

O índice de intensidade de brotação foliar foi de 33\% na área 1, e de 15\% na área 2, no ano de 2015. Os índices em 2016 foram de 33 e 32\% nas áreas 1 e 2, nesta ordem.

Pirani, Sanchez e Pedroni (2009) avaliaram os eventos fenológicos de uma comunidade arbórea em Cerrado sentido restrito, no município de Barra do GarçasMT, e observaram que algumas das espécies apresentaram elevada intensidade de brotação durante a transição da estação seca para chuvosa, entre os meses de setembro e novembro. De forma similar, a emissão de brotos em indivíduos de Byrsonima basiloba, descrita por Silva et al. (2016), foi verificada em meados do período seco, na transição deste para o chuvoso e durante a época chuvosa.

É fundamentado na literatura que a precipitação contribui para o surgimento das gemas vegetativas, porém a brotação foliar se correlacionou negativamente apenas com a umidade relativa do $\operatorname{ar}\left(r_{s}=-0,50\right)$ na área 1 , e $\left(r_{s}=-0,58\right)$ na área 2. Isso difere do encontrado por Santos, Coelho e Pirani (2009), em que a brotação de Lafoensia pacari apresentou correlação positiva com as temperaturas mínima e máxima (Tabela 1).

\subsection{Fenofases reprodutivas}

Na área 1, indivíduos com botões florais foram observados no final do período chuvoso e por todo o período seco, entre os meses de maio a julho de 2015 e de abril a agosto de 2016. Foram observados botões florais em até 40\% dos indivíduos no mês de junho, nos dois anos de avaliação. 
O período de observação de botões florais foi menor em 2015, durando três meses em ambas as áreas. Na área 2, o registro de botões florais ocorreu em 4\% dos indivíduos nos meses de maio e julho de 2015 e março de 2016 (Figura 3).

Figura 3 - Índice de atividade (a) e (b) e de intensidade (c) e (d) em relação à floração (Botão floral e Flores abertas) de 50 indivíduos amostrados de Lafoensia pacari St. Hill., em duas áreas de Cerrado Mato-Grossense

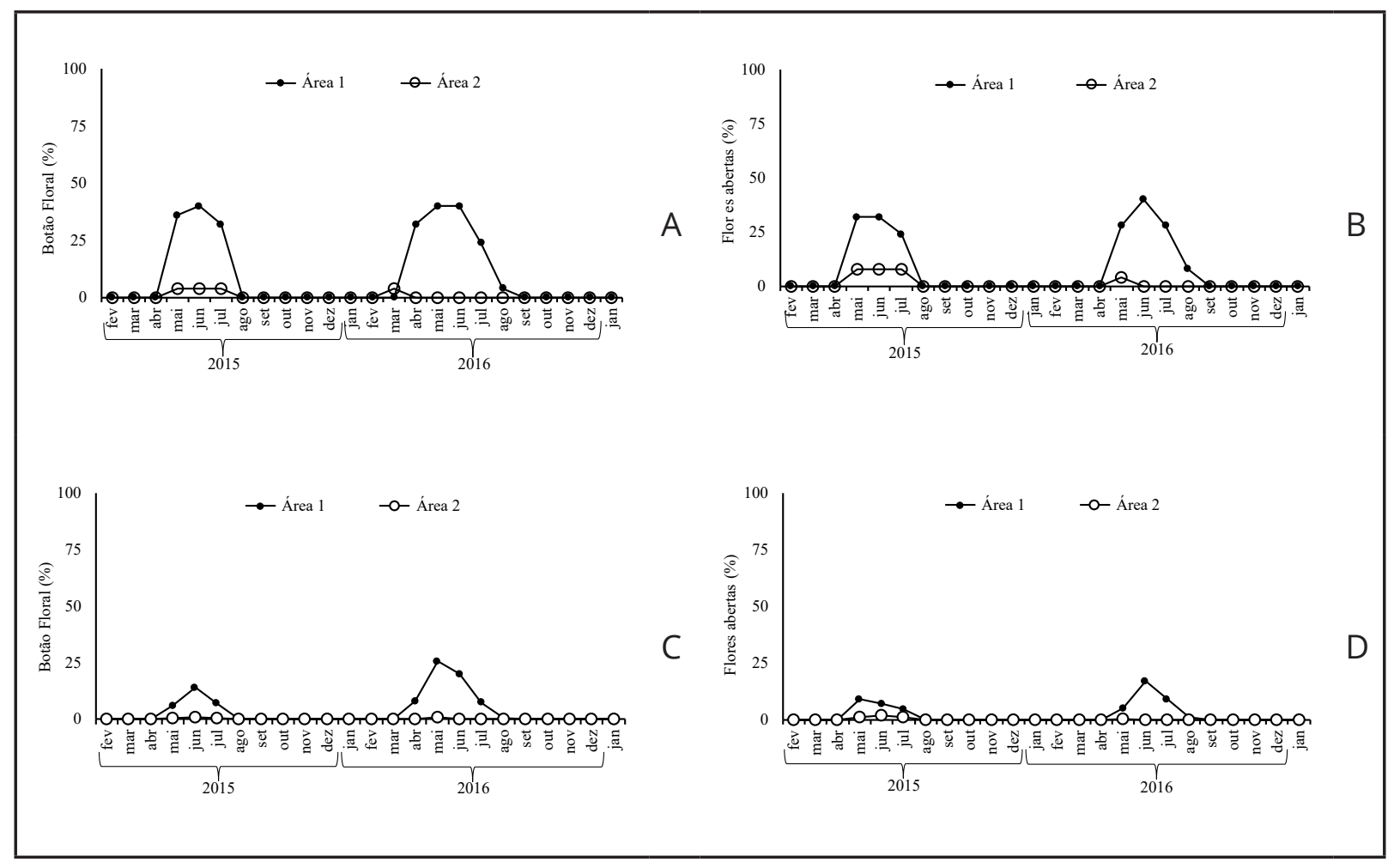

Fonte: Autores (2020)

Na área 1, o pico de intensidade dos botões florais ocorreu em junho de 2015 e em maio de 2016, com 14 e 25\%, respectivamente. O índice de intensidade de botões foi inferior a 2\% na área 2 . Nos dois anos de observação, no mês de junho, foram registrados os menores valores de temperaturas mínima e máxima, indicando uma forte relação do aparecimento dos botões florais com a temperatura, reforçado pelas correlações significativas negativas com as temperaturas máximas $\left(r_{s}=-0,73\right)$ e minima $\left(r_{s}=-0,73\right)$ e com a precipitação $\left(r_{s}=-0,63\right)$ na área 1. Na área 2, a fenofase de 
botões florais não se correlacionou com nenhuma das variáveis climáticas analisadas, provavelmente devido à baixa produção de flores (Tabela 2).

Tabela 2 - Coeficientes de correlação de Spearman $\left(r_{s}\right)$ entre precipitação total mensal, temperatura máxima, temperatura mínima e umidade relativa, e a porcentagem de indivíduos de Lafoensia pacari St. Hill., nas fenofases botões florais (Bf), flores abertas (Fa), frutos imaturos (Fi) e frutos maduros (Fm)

\begin{tabular}{|c|c|c|c|c|c|c|}
\hline \multirow[b]{2}{*}{ Variável ambiental } & \multicolumn{3}{|c|}{ Área 1} & \multicolumn{3}{|c|}{ Área 2} \\
\hline & Fenofase & rs & $p$ & Fenofase & rs & $p$ \\
\hline \multirow{4}{*}{ UR (\%) } & $\mathrm{Bf}$ & $-0,20$ & 0,33 & $\mathrm{Bf}$ & 0,02 & 0,91 \\
\hline & $\mathrm{Fa}$ & $-0,22$ & 0,29 & $\mathrm{Fa}$ & $-0,06$ & 0,77 \\
\hline & $\mathrm{Fi}$ & $-0,60$ & $0,001 *$ & $\mathrm{Fi}$ & - & - \\
\hline & $\mathrm{Fm}$ & $-0,19$ & 0,35 & $\mathrm{Fm}$ & - & - \\
\hline \multirow{4}{*}{ Temp. Máx. $\left({ }^{\circ} \mathrm{C}\right)$} & $\mathrm{Bf}$ & $-0,73$ & 0,0001 * & $\mathrm{Bf}$ & 0,18 & 0,39 \\
\hline & $\mathrm{Fa}$ & $-0,77$ & $0,0001 *$ & $\mathrm{Fa}$ & $-0,56$ & $0,004 *$ \\
\hline & $\mathrm{Fi}$ & $-0,02$ & 0,91 & $\mathrm{Fi}$ & - & - \\
\hline & $\mathrm{Fm}$ & $-0,11$ & 0,94 & $\mathrm{Fm}$ & - & - \\
\hline \multirow{4}{*}{ Temp. Mín. $\left({ }^{\circ} \mathrm{C}\right)$} & $\mathrm{Bf}$ & $-0,73$ & 0,0001 * & $\mathrm{Bf}$ & $-0,40$ & 0,05 \\
\hline & $\mathrm{Fa}$ & $-0,79$ & 0,0001 * & $\mathrm{Fa}$ & $-0,56$ & $0,003 *$ \\
\hline & $\mathrm{Fi}$ & $-0,04$ & 0,84 & $\mathrm{Fi}$ & - & - \\
\hline & $\mathrm{Fm}$ & 0,13 & 0,52 & $\mathrm{Fm}$ & - & - \\
\hline \multirow{4}{*}{ Precipitação (mm) } & $\mathrm{Bf}$ & $-0,63$ & $0,0009 *$ & $\mathrm{Bf}$ & $-0,24$ & 0,25 \\
\hline & $\mathrm{Fa}$ & $-0,63$ & $0,0008 *$ & $\mathrm{Fa}$ & $-0,44$ & $0,02 *$ \\
\hline & $\mathrm{Fi}$ & $-0,51$ & $0,01 *$ & $\mathrm{Fi}$ & - & - \\
\hline & $\mathrm{Fm}$ & $-0,07$ & 0,72 & $\mathrm{Fm}$ & - & - \\
\hline
\end{tabular}

Fonte: Autores (2020)

Em que: $\left.{ }^{*}\right)$ Correlação significativa a $5 \%$ de probabilidade $(p<0,05)$.

Estudos realizados com Curatella americana em um Cerrado na região de Tangará da Serra-MT constataram o processo de floração a partir do mês de junho, em que $80 \%$ das amostras apresentaram a emissão de botões e inúmeras flores abertas, cujo pico de floração foi observado no mês de agosto nos dois anos de avaliação, 2007 e 2008 (SANTOS; AÑEZ, 2018). 
A abertura das flores ocorreu no final do período chuvoso e por todo o período seco na área 1. A antese no início do período chuvoso também foi verificada em indivíduos de Qualea parviflora em um Cerrado Sul-Mato-Grossense (FERREIRA et al., 2017). Entre os meses de maio a julho de 2015 e de maio a agosto de 2016 foram observadas flores abertas. Foram visualizadas flores em até 32 e $40 \%$ dos indivíduos no mês de junho, nos anos de 2015 e 2016, simultaneamente. A antese ocorreu de forma reduzida na área 2, com 8\% dos indivíduos entre maio e julho de 2015 e 4\% em março de 2016. Na área 1, o pico de intensidade das flores ocorreu em maio de 2015 e em junho de 2016, com 9 e 17\%, respectivamente. O índice de intensidade de floração atingiu valores inferiores a 2\% na área 2 (Figura 3). Santos, Coelho e Pirani (2009), em Barra do Garças-MT, registraram presença de flores de Lafoensia pacari nos meses de abril a julho de 2004 e junho a agosto de 2005, com maior intensidade da fenofase nos meses de maio de 2004 e agosto de 2005. Tais resultados são similares aos encontrados neste trabalho, no qual a floração ocorreu no final das chuvas e prolongou-se por todo o período seco.

As correlações da abertura das flores foram significativamente negativas com as temperaturas máxima $\left(r_{s}=-0,77\right.$ e $\left.r_{s}=-0,56\right)$ e mínima $\left(r_{s}=-0,79\right.$ e $\left.r_{s}=-0,56\right)$ nas áreas 1 e 2, respectivamente, e com a precipitação $\left(r_{s}=-0,66\right)$ na área 1. Segundo Santos, Coelho e Pirani (2009), a floração na época de seca parece ser o padrão mais comum da vegetação arbórea do Cerrado e de savanas, visto que, em seus estudos fenológicos, a floração de Lafoensia pacari mostrou correlação negativa com a precipitação e a temperatura mínima.

Indivíduos de Byrsonima umbellata, que também são importantes componentes da flora do Cerrado, apresentaram extenso período de floração, entre os meses de março a outubro, todavia, todos os indivíduos amostrados floresceram nos meses de junho e julho, meses com baixos índices de chuva (MENDES; RÊGO; ALBUQUERQUE, 2012). Belo et al. (2019) observaram o florescimento de Anacardium othonianum durante o período de baixa precipitação. Entretanto, nos estudos de Silva et al. (2016), a emissão 
de botões florais e da abertura das flores de Byrsonima basiloba foi sazonal, durante a estação chuvosa, nos dois anos de observação, assim como para Silva et al. (2015) que observaram a floração de Hylocereus undatus em um Cerrado em Jaboticabal-SP, predominantemente em novembro, nos dois ciclos de produção avaliados, com cerca de $35 \%$ do total emitido durante o período de novembro a março, coincidindo com altas temperaturas e início da estação chuvosa.

Alguns autores alegam que o florescimento em épocas de seca ou no início das chuvas que ocorre no Cerrado (FERREIRA et al. 2017; SILVA, 2016), favorecem a atividade polinizadora, já que a ausência de chuvas, ou chuvas em menores intensidades não causariam danos às estruturas florais (JANZEN, 1980; MENDES; RÊGO; ALBUQUERQUE, 2012). Ao estudarem a relação da biologia floral da Lafoensia pacari com seus agentes polinizadores, Sazima e Sazima (1974) observaram a visita noturna de três espécies de morcegos nos meses de julho e setembro, períodos caracterizados pela baixa taxa de precipitação.

Outro fator que ficou comprovado durante as observações da floração foi a baixa porcentagem de abertura das flores em relação à produção de botões florais, nos dois anos de observação. Esse mesmo comportamento foi evidenciado por Silva et al. (2016) ao estudarem a fenologia reprodutiva de indivíduos de Byrsonima basiloba no Cerrado goiano.

Um dos motivos que explica essa diminuição de flores abertas e, consequentemente, de frutos da Lafoensia pacari, é a alta predação das flores observadas em campo. Durante as observações fenológicas foram encontrados vestígios das flores no chão nas proximidades dos indivíduos, sendo que muitas vezes, ainda na árvore, as flores apresentavam as estruturas danificadas.

A frutificação apresentou padrão anual. Frutos imaturos foram observados entre os meses de julho e setembro de 2015, na área 1, com 8\% dos indivíduos apresentando o evento. A frutificação em 2016 ocorreu nos meses de julho e agosto, com $20 \%$ dos indivíduos apresentando frutos imaturos na área 1. Na área 2, o evento não se manifestou em todo o período de observação (Figura 4). 
A observação dos frutos imaturos coincidiu com o final do período seco e início do chuvoso, indicando que a frutificação da espécie depende da hidratação dos tecidos para o início do processo, bem como a produção de frutos de Hymenaea stigonocarpa (SILVA, 2018) que também começou em meados do período chuvoso. Esse processo pode indicar uma estratégia da espécie para que a dispersão ocorra nas chuvas preliminares, e as sementes encontrem condições hídricas favoráveis para iniciar o processo de germinação.

Figura 4 - Índice de atividade (a) e (b) e de intensidade (c) e (d) em relação à Frutificação (Frutos verdes e Frutos maduros) de 50 indivíduos amostrados de Lafoensia pacari St. Hill., em duas áreas de Cerrado Mato-Grossense

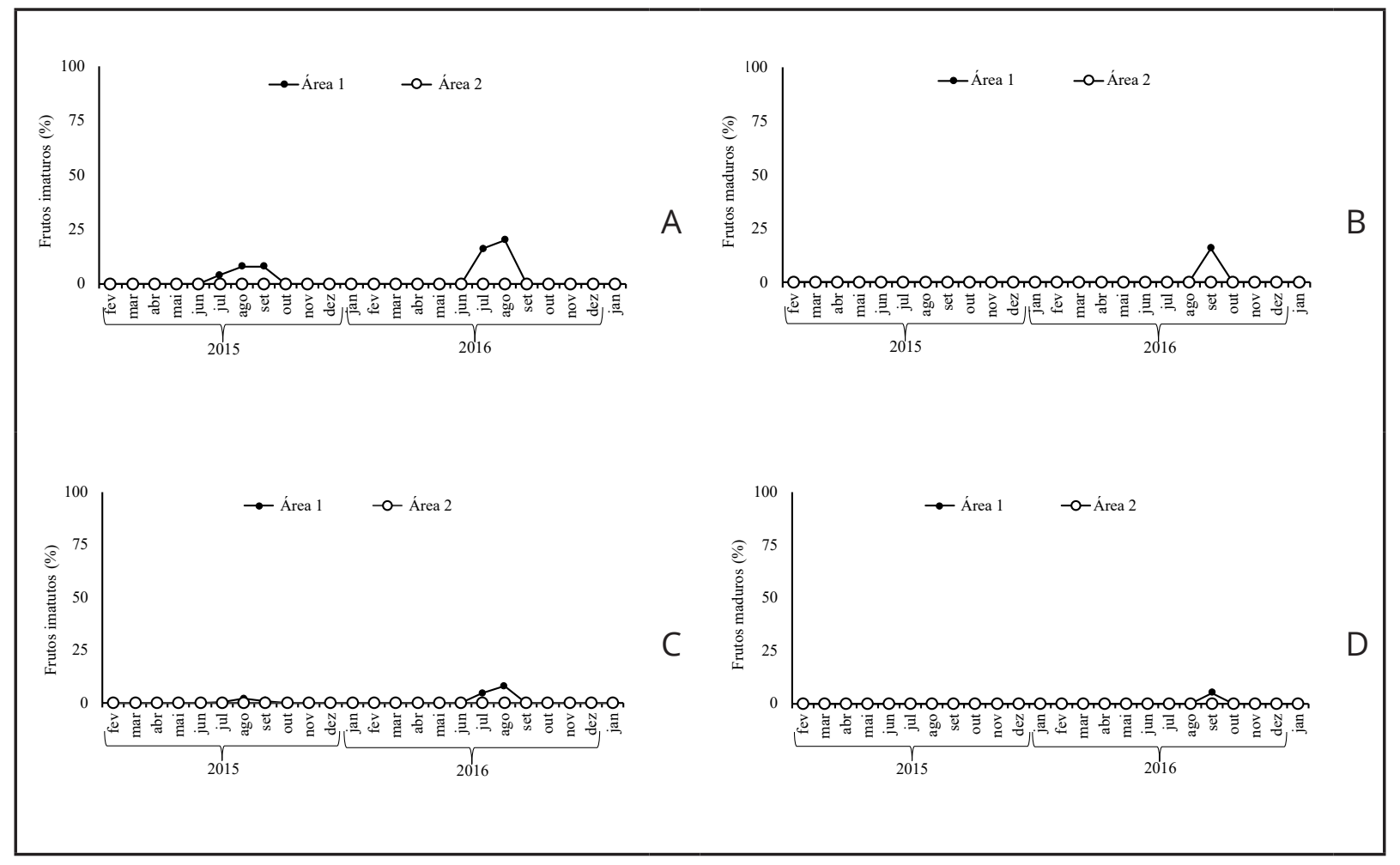

Fonte: Autores (2020)

Moura, Oliveira e Chaves (2010) observaram que a frutificação de Solanum lycocarpum, em Morrinhos-GO, ocorreu em dois picos, um em novembro e outro em abril, ambos os meses apresentaram valores consideráveis de precipitação. Da mesma forma, Pirani, Sanchez e Pedroni (2009) verificaram que o início da estação 
chuvosa favoreceu a ocorrência de picos de frutificação e a dispersão dos diásporos das espécies em Barra do Garças-MT.

O índice de intensidade de frutos imaturos apresentou valores inferiores a $8 \%$ na área 1. Na área 2, não foram observados frutos imaturos. A fenofase frutos imaturos correlacionou-se negativamente com a umidade relativa $\left(r_{s}=-0,60\right)$ e com a precipitação $\left(r_{s}=-0,51\right)$. Na área 1 , a ocorrência de frutos maduros foi observada apenas no segundo ano de avaliação, atingindo o pico de atividade em setembro, com 16\% dos indivíduos apresentando o evento. Na área 2, o evento não se manifestou nos dois anos de avaliação (Figura 4). O índice de intensidade de frutos maduros foi baixo na área 1, apenas 5\%. Na área 2, o evento não foi observado.

Silvério e Lenza (2010) avaliaram a fenologia de espécies lenhosas de um Cerrado típico no Parque Municipal do Bacaba, Nova Xavantina-MT, e identificaram variação na proporção de frutos imaturos e maduros. A espécie Qualea grandiflora, em 12 meses, praticamente não produziu frutos, bem como Ouratea spectabilis, Kielmeyera rubrifora e Byrsonima pachyphylla, que apresentaram baixa produção de frutos maduros.

Embora a maturação dos frutos tenha coincidido com o início do período chuvoso, o evento não se correlacionou com nenhuma das variáveis ambientais. Com relação ao comportamento fenológico, os indivíduos localizados na área 1 apresentaram maiores índices de atividade e intensidade, principalmente relacionados às fenofases reprodutivas, ou seja, as variações na fitofisionomia do Cerrado influenciaram na ocorrência dos eventos fenológicos desse Bioma. Dessa forma, os dados obtidos neste trabalho podem ajudar a fomentar estudos futuros sobre manejo, produção, cultivo e coleta de sementes de Lafoensia pacari nas variadas formações do Cerrado.

\section{CONCLUSÕES}

Lafoensia pacari é uma espécie com intensa senescência das folhas no auge do período seco. A floração é sazonal no período seco, relacionando-se com precipitação e temperaturas menores. A frutificação apresenta padrão anual sazonal no início do período chuvoso, porém, com baixa intensidade. 
Os indivíduos da área de Cerradão apresentam comportamentos distintos quando comparados aos do Cerrado sentido restrito, principalmente das fenofases reprodutivas.

\section{REFERÊNCIAS}

BELO, A. P. M. et al. Fenologia, biometria e precocidade de plantas de caju arbóreo do cerrado (Anacardium othonianum Rizz.). Ciência Florestal, Santa Maria, v. 29, n. 4, p. 1672-1648, 2019.

BENCKE, C. S. C.; MORELLATO, L. P. C. Comparação de dois métodos de avaliação da fenologia de plantas, sua interpretação e representação. Revista Brasileira de Botânica, São Paulo, v. 25, n. 3, p. 269-275, 2002.

BRAGA, A. M. S. et al. Fenologia de três espécies arbóreas em um trecho de vegetação subcaducifólia no norte do Piauí, Brasil. Biotemas, Florianópolis, v. 32, n. 2, p. 33-44, 2019.

CABRAL, P. R. F.; PASA, M. C. Mangava-brava: Lafoensia pacari a. st. - hil. (lythraceae) e a Etnobotânica em Cuiabá-MT.Revista Biodiversidade, Rondonópolis,v. 8, n. 1, 2009.

DALMOLIN, A. C. et al. Is the dry season an important driver of phenology and growth for two Brazilian savanna tree species with contrasting leaf habits? Plant Ecology, Dordrecht, v. 216, n. 3, p. 407-417, 2015.

FARIA, R. A. P. G. et al. Fenologia de Brosimum gaudichaudii trécul. (Moraceae) no cerrado de Mato Grosso. Ciência Florestal, Santa Maria, v. 25, n. 1, p. 67-75, 2015.

FERREIRA, K. R. et al. Fenologia de Qualea parvoflora Mart. (Vochysiaceae) em um remanescente de cerrado sensu scrito. Revista de Agricultura Neotropical, Cassilândia, v. 4, n. 3, p. 15-22, 2017.

FOURNIER, L. A. Un método cuantitativo para la medición de características fenológicas em árbores. Turrialba, Costa Rica, v. 24, n. 4, p. 422-423, 1974.

FURQUIM, L. C. et al. Relação entre plantas nativas do Cerrado e água. Multidisciplinary Journal, Anápolis, v. 5, n. 2, p. 146-156, 2018.

FREIRE, J. M. et al. Fenologia reprodutiva de espécies arbóreas em área fragmentada de Mata Atlântica em Itaborai, RJ. Pesquisa Florestal Brasileira, Colombo, v. 33, n. 75, p. 243-252, 2013.

JANZEN, D. H. Ecologia vegetal nos trópicos. São Paulo: EPU; EDUSP, 1980. 79 p.

MENDES, F. N.; RÊGO, M. M. C.; ALBUQUERQUE, P. M. C. Fenologia e biologia reprodutiva de duas espécies de Byrsonima Rich. (Malpighiaceae) em área de Cerrado no Nordeste do Brasil. Biota Neotropica, Campinas, v. 11, n. 4, p. 103-115, 2012. 
MORELLATO, L. P. C. et al. Linking plant phenology to conservation biology. Biological Conservation, Washington, v. 195, p. 60-72, 2016.

MOURA, T. M.; OLIVEIRA, G. C. X.; CHAVES, L. J. Correlação entre floração, frutificação e variáveis ambientais em Solanum lycocarpum. A. St. Hil, Solanaceae. Bioscience Journal, Uberlândia, v. 26, n. 3, p. 457-462, 2010.

MUNHOZ, C. R. B.; FELFILI, J. M. Reproductive phenology of an herbaceous-subshrub layer of a Savannah (Campo Sujo) in the Cerrado Biosphere Reserve I. Brazil. Brazilian Journal of Biology, São Carlos, v. 67, n. 2, p. 299-307, 2007.

OLIVEIRA, P. E. Fenologia e biologia reprodutiva das espécies de Cerrado. In: SANO, S. M.; ALMEIDA, S. P. (ed.). Cerrado: ambiente e flora. Planaltina: Embrapa Cerrados, 2008. p. 169188.

PEREIRA, T. S. et al. Fenologia de espécies arbóreas em Floresta Atlântica da Reserva Biológica de Poço das Antas, Rio de Janeiro, Brasil. Iheringa, Série Botânica, Porto Alegre, v. 63, n. 2, p. 329-339, 2008.

PIAUILINO, S. A. C. et al. Estudo fenológico de Lafoensia replicata Pohl. No município de Bom Jesus, Piauí. Scientia Plena, [s. I.], v. 8, n. 4, p. 1-5, 2012.

PIRANI, F. R.; SANCHEZ, M.; PEDRONI, F. Fenologia de uma comunidade arbórea em cerrado sentido restrito, Barra do Garças, MT, Brasil.Acta Botânica Brasilica, São Paulo, v. 23, n. 4, p. 1096-1109, 2009.

PIRES, H. C. G. et al. Padrão Fenológico de Attalea maripa (Aubl.) Mart. em Áreas de Pastagens na Amazônia Oriental. Floresta e Ambiente, Rio de Janeiro, v. 23, n. 2, p. 170-179, 2016.

RATHCKE, B.; LACEY, E. P. Phenological Patterns os Terrestrial Plants. Annual Review of Ecology and Systematics, Palo Alto, v. 16, p. 179-214, 1985.

SANTOS, L. W.; COELHO, M. F. B; PIRANI, F. R.Fenologia de Lafoensia pacari A.St.-Hil. (Lythraceae) em Barra do Garças, Mato Grosso, Brasil. Revista Brasileira de Plantas Medicinais, Botucatu, v. 11, n. 1, p. 12-17, 2009.

SANTOS, R. A.; AÑES, R. B. S. Aspectos da biologia floral de Curatella americana L. (DILLENIACEAE), em um fragmento de Cerrado antropizado, Tangará da Serra, MT. Flovet, [s. I.], v. 1, n. 10, p. 22-36, 2018.

SAZIMA, M.; SAZIMA, I. Quiropterofilia em Lafoensi pacari St. Hill. (Lythraceae), na Serra do Cipó, Minas Gerais. Ciência e Cultura, [s. I.], v. 27, n. 4, p. 405-416, 1975.

SILVA, A. C. C. et al. Fenologia reprodutiva da pitaya vermelha em Jaboticabal, SP. Ciência rural, Santa Maria, v. 45, n. 4, p. 585-590, 2015.

SILVA, P. O. Estratégias fenológicas reprodutivas de Xylopia aromática (LAM.) MART. (ANNONACEAE) em área de Cerrado. Cerne, Lavras, v. 22, n. 1, p. 129-135, 2016.

SILVA, P. O. Fenologia reprodutiva de Hymenaea stignocarpa Mart ex Hayne (Fabaceae) em Cerrado sensu scrito. Acta Biológica catarinense, Joinville, v. 5, n. 2, p. 89-97, 2018. 
SILVA, P. O. et al. Estratégias fenológicas de Byrsonima basiloba em Rio Verde, Goiás, Brasil. Pesquisa Florestal Brasileira, Colombo, v. 36, n. 87, p. 289-295, 2016.

SILVA, V. C. et al. A new antifungal phenolic glycoside derivative, iridoids and lignans from Alibertia sessilis (Vell.) K. Schum. (Rubiaceae). Journal Brazilian Chemical Society, São Paulo, v. 18, n. 7, p. 1405-1409, 2007.

SILVÉRIO, D. V.; LENZA, E. Phenology of woody species in a typical cerrado in the Bacaba Municipal Park, Nova Xavantina, Mato Grosso, Brazil. Biota Neotropica, Campinas, v. 10, n. 3, p. 205-216, 2010.

SOUZA, D. N. N. et al. Estudo fenológico de espécies arbóreas nativas em uma unidade de conservação de caatinga no Estado do Rio Grande do Norte, Brasil. Biotemas, Florianópolis, v. 27, n. 2, p. 31-42, 2014.

ZAR, J. H. Biostatistical analysis. New Jersey: Prentice-Hall, 1996. 662 p.

\section{Contribuição de Autoria}

\section{1 - Reinaldo de Souza Bílio}

Engenheiro Florestal, Doutorando

https://orcid.org/0000-0001-6777-9600•reinaldobilio@hotmail.com

Contribuição: Conceituação, Curadoria de dados, Análise Formal, Obtenção de financiamento, Investigação, Metodologia, Administração do projeto, Recursos, Supervisão, Validação, Visualização de dados, Escrita - primeira redação, Escrita revisão e edição

\section{2 - Maria de Fatima Barbosa Coelho}

Engenheira Agrônoma, Dra., Professora

https://orcid.org/0000-0003-1393-2504•coelhomfstrela@gmail.com

Contribuição: Conceituação, Análise Formal, Obtenção de financiamento, Investigação, Metodologia, administração do projeto, Recursos, Supervisão, Validação, Visualização de dados, Escrita - primeira redação, Escrita - revisão e edição

\section{3 - Elisângela Clarete Camili}

Engenheira Agrônoma, Dra., Professora

https://orcid.org/0000-0002-4642-2511 • eccamili@hotmail.com

Contribuição: Análise Formal, Metodologia, Recursos, Escrita - primeira redação, Escrita - revisão e edição 


\section{4 - Flávia Richelli Pirani}

Graduação em Ciências Biológicas e da Saúde, Dra., Pesquisadora Autônoma https://orcid.org/0000-0001-5695-7977• flaviarichelli@yahoo.com.br

Contribuição: Curadoria de dados, Análise Formal, Escrita - revisão e edição

\section{5 - Simone dos Santos da Silva}

Bióloga, Pesquisadora Autônoma

https://orcid.org/0000-0002-1416-3172•simonebotanica.23@gmail.com

Contribuição: Curadoria de dados, Investigação

\section{Como citar este artigo}

Bílio, R. S.; Coelho, M. F. B.; Camili, E. C.; Pirani, F. R.; Silva, S. S. Fenologia de Lafoensia pacari St. Hill. em duas fitofisionomias do Cerrado Mato-Grossense. Ciência Florestal, Santa Maria, v. 31, n. 3, p. 1147-1166, 2021. DOI 10.5902/1980509835718. Disponível em: https://doi. org/10.5902/1980509835718. Acesso em: xx mês-abreviado 2021. 